\title{
ANTENA ARGENTA: relato de usos das redes sociais para difusão de literatura argentina no Brasil
}

ANTENA ARGENTA: Relato de uso de la redes sociales para difusión de literatura argentina en Brasil

ANTENA ARGENTA: an account on the use of social media for the dissemination of Argentinian literature in Brazil

\section{Davidson Diniz ${ }^{1}$}

RESUMO: Este texto é um relato de uso das redes sociais na produção e difusão de conteúdos e atividades relacionadas à página ANTENA ]A[ RGENTA - canal de literatura argentina no Brasil. Trata-se de um projeto elaborado com a intenção de produzir material próprio, bem como divulgar eventos relacionados à circulação da literatura argentina no Brasil e da literatura brasileira na Argentina. E com isso pensar as dinâmicas atuais dos dispositivos de circulação bilateral entre nosso binômio.

Palavras-chave: Redes Sociais; Literatura Argentina; Literatura Brasileira; Tradução.

RESUMEN: Este texto es un relato de uso de las redes sociales en tanto producción y difusión de contenidos y actividades relacionadas a la pagina (web) ANTENA ]A[ RGENTA - canal de literatura argentina en Brasil. Se trata de un proyecto elaborado con la intención de producir material própio, bien como divulgar eventos vinculados a la circulación de la literatura argentina en Brasil y de la literatura brasileña en Argentina. Y con ello pensar las dinámicas vigentes de los dispositivos de circulación bilateral entre nuestro binómio.

Palabras-clave: Redes Sociales; Literatura Argentina; Literatura Brasileña; Traducción.

ABSTRACT: This text is an account on the use of social media for the production and dissemination of content and activities related to the ANTENA]A[RGENTA webpage - a

Submetido em: 07/09/2020 - Aceito em: 27/11/2020 - Publicado em: 24/12/2020

${ }^{1}$ USP-FAPESP. Email: davis.diniz@gmail.com 
channel of Argentinian literature in Brazil. This is a project designed with the intention of producing its own content, as well as divulging events related to the circulation of Argentinian literature in Brazil and of Brazilian literature in Argentina. As an extension of this, it aims to contemplate on the current dynamics of the bilateral circulation devices between our binomial.

Keywords: Social Media; Argentinian Literature; Brazilian Literature; Translation.

\section{INTRODUÇÃO}

ANTEN ]A[ RGENTA ${ }^{2}$ é uma página criada em junho de 2020 com a intenção de produzir e difundir conteúdos de literatura argentina no Brasil. Trata-se de um projeto experimental (em oposição ao que chamaríamos de institucional) idealizado em vista de trabalhos de crítica literária desenvolvidos dentro das universidades brasileiras e argentina ao longo dos últimos anos, ${ }^{3}$ bem como de traduções de literatura argentina no meio editorial brasileiro. ${ }^{4}$ Por ser experimental, o projeto não conta com nenhum tipo de fomento financeiro, ocorrendo de maneira estritamente espontânea e colaborativa.

Frente à nova realidade de sociabilidade imposta pela pandemia, houve uma proliferação de eventos (lives, webnários, apresentação de livros, etc.) nas redes sociais. Dada a gravidade da crise sanitária, bem como a ausência de planejamento sistemáticos do Ministério

\footnotetext{
${ }^{2}$ https://davisdiniz.wixsite.com/antenargenta

${ }^{3}$ Períodos do meu doutorado (Faculdade de Letras da UFMG, 2010-2014) e do pós-doc (Departamento de Sociologia da USP, 2017-atual) foram realizadas na Universidade de Buenos Aires. A partir de 2013, inserido no grupo de pesquisadores coordenados pela professora Marcela Croce (titular da cátedra de Problemas de Literatura Latino-Americana da UBA), produzimos a primeira história comparada das literaturas argentina e brasileira, obra já publicada em seis volumes pela Editorial Universitaria de Villa María (EDUVIM) entre 2016 e 2019 e em curso de tradução e edição no Brasil (Editora Autêntica \& UFMG). A tarefa nos permitiu a todo o grupo dialogar com estudos precedentes, bem como abrir novos caminhos para o comparatismo bilateral de nossos dois países. Da minha parte, entre outros assuntos, escrevi capítulos sobre diversos autores, editores e tradutores (Monteiro Lobato, Manuel Gálvez, Benjamín de Garay, Raúl Navarro, Lídia Besouchet, Newton Freitas, etc.) determinantes para a circulação bilateral ente Argentina e Brasil.

${ }^{4}$ Junto da pesquisa acadêmica, venho desde 2013 traduzindo e publicando escritores e poetas argentinos no Brasil, a exemplo de Roberto Arlt (Relicário Edições, 2014), Alejandra Pizarnik (Relicáriio Edições, 2018), Elvio Gandolfo (Papeis Selvagens, 2019), Diego Meret (Papeis Selvagens, prelo).
} 
da Saúde no Brasil, ficou perceptível que várias ações vinculadas às universidades e às pesquisas acadêmicas, não diferindo do restante da sociedade, seriam longamente afetadas pelo urgência do confinamento protetivo. E portanto me pareceu oportuno catalisar algo das tarefas vinculadas à minha pesquisa atual e expandir sua circulação ao experimentar também o diálogo por meio das redes sociais.

A primeira etapa foi criar uma página na web. Após avaliar as ofertas de sites gratuitos, optei, considerando a sobriedade do desenho gráfico, por uma conta na plataforma Wix.com:

\section{ANTEN ]A[ RGENTA ::: GABRIELA CABEZÓN CÁMARA (entrevista ${ }^{*}$ )}
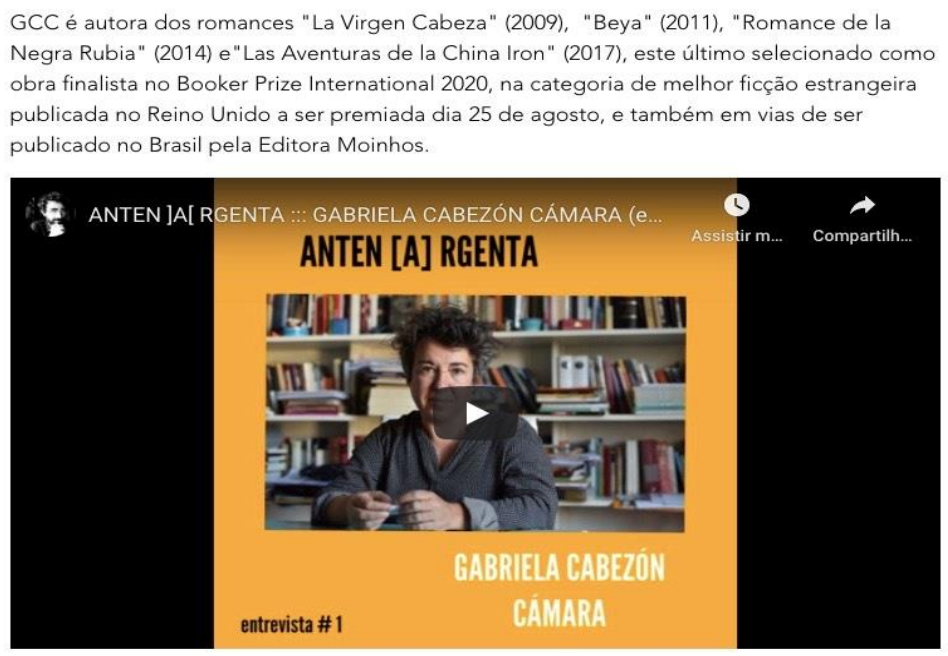

[fragmento com a aparência da página web]

Daí por diante a página passou a ser divulgada em perfis vinculados ao Instagram e ao Facebook. Primeiramente, por meio de uma tradução para o poema "Cadáveres", do antropólogo, poeta e ensaísta argentino Nestor Perlongher, autor que viveu e atuou vários anos no Brasil, tendo se tornado Professor Adjunto na UNICAMP a partir de finais dos anos 1980. "Cadáveres" - poema longo e de tom elegíaco composto frente ao genocídio argentino e por extensão latino-americano produzido nos contextos das últimas ditaduras cívico-militares do nosso continente e que levara Perlongher ao exílio brasileiro - foi escolhido por dois motivos: 
permitia (pela biografia e militância de seu autor) uma operação tradutória capaz de vincular o texto diretamente ao contexto brasileiro do período dos regimes militares, bem como enfatizar no presente da recepção o problema da mortandade massiva no Brasil em função da falta de planejamento sanitário e da inaptidão explícita do nosso poder executivo ao longo de 2020 . O texto de Perlongher revelaria, segundo nosso entendimento, uma sincronia com os debates públicos daqueles e destes tempos, posto que recentemente a sociedade brasileira veio a indagar o ressurgimento da figura do genocida entre nós. Na sequência da tradução de "Cadáveres" foi feita uma entrevista com a escritora argentina Gabriela Cabezón Cámara, autora do livro Las aventuras de la China Iron (2017), uma das obras literárias argentinas mais lidas e comentadas dos últimos anos, finalista do prêmio Booker Prize Internacional 2020, e cujos direitos autorais, conforme revelado na entrevista, acabavam de ser comprados pela editora brasileira Moinhos (Belo Horizonte).

Essas duas atividades, a tradução de Perlongher e a entrevista com Cabezón Cámara, cumpriam de entrada dois dos principais motivos que levaram à criação da nossa página: divulgar traduções inéditas e edições de literatura argentina ou em curso de publicação no Brasil. Fizemos então mais uma entrevista, com o sociólogo brasileiro Sergio Miceli (2012, 2018), autor cuja última série de ensaios interpelou comparativamente o contexto das vanguardas argentina e brasileira, interpelando também a morfologia do campo intelectual argentino vinculado ao grupo da revista SUR nos anos 1930 e 1940.

Atualmente estamos preparando outras entrevistas, que futuramente serão divulgadas em nossa página. E demos a conhecer também uma outra série de atividades, denominada “autor@s.leem”. Trata-se de leituras de poetas argentinos, seguidas de traduções dos textos originais ainda não publicados no Brasil ou não de todo conhecidos entre nós. Para isso, contamos com a mediação do poeta e narrador argentino Salvador Biedma, convidado a participar em nossa página com seus próprios textos e logo incumbido de selecionar e enviar para a ANTENA ]A[ RGENTA uma leva de escritores contemporâneos cujos poemas estamos traduzindo e divulgando na página. 

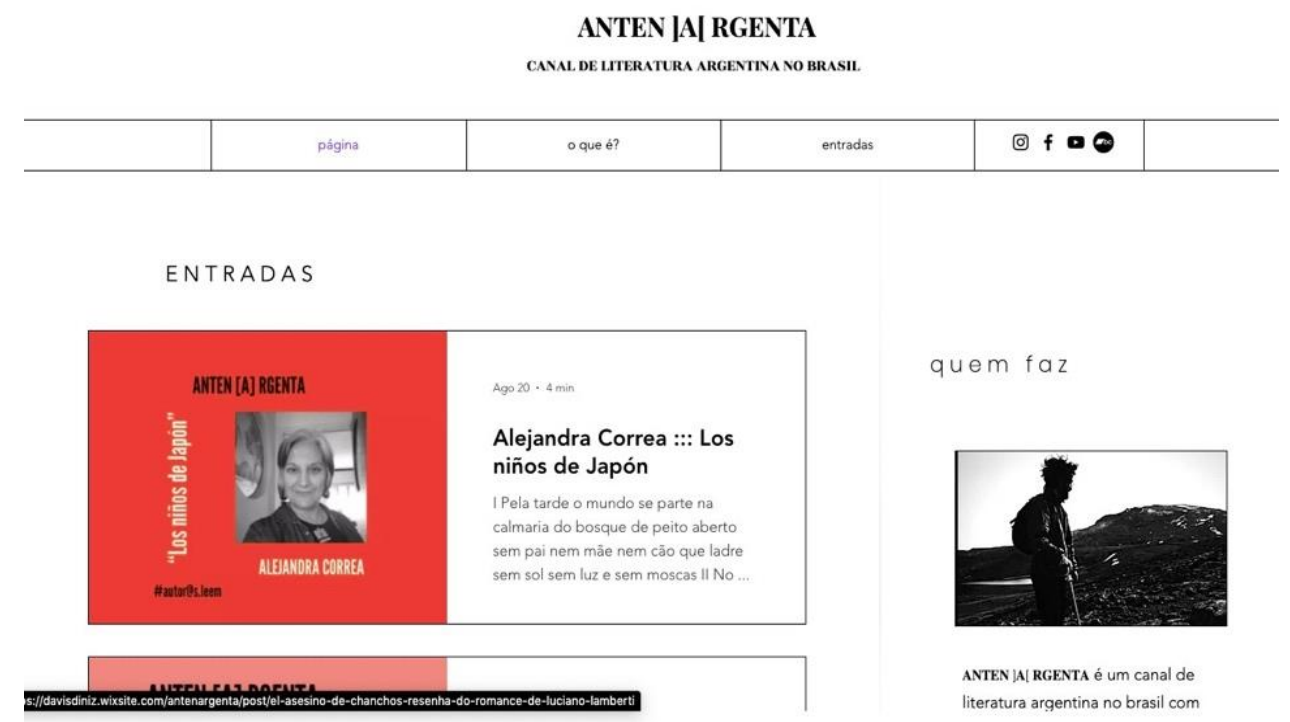

quem faz

[fragmento com imagem da sessão “autor@ s.lee,”]

A série "autor@s.leem” está atualmente em curso de divulgação. Até aqui foram apresentadas seis entradas em nossa página, e estamos preparando material para subir o restante da leva. Futuramente, quando fecharmos o ciclo argentino, passaremos a preparar um ciclo brasileiro. Ou seja: apresentar uma antologia (entre dez a quinze nomes) de poetas brasileiros, eles próprios lendo seus poemas em vídeo, e traduzidos ao espanhol (com a colaboração de Biedma desta vez) para assim serem apresentados na página. Consideramos - numa etapa a vir após as publicações na página - a possibilidade de transformar tal material em uma antologia bilíngue, com poetas tanto da Argentina quanto do Brasil, e assim oferecer o projeto a algum selo editorial potencialmente interessado em tal publicação.

Interessa destacar que as sessões “autor@s.leem” (para além da divulgação dos poetas e da tentativa de colaborar para as dinâmicas poéticas e editoriais ambiláteras), uma vez trazendo (ao lado dos textos escritos e traduzidos) as leituras de poetas de origem não só portenha, mas cordobesa, rosarina, entrerriana, e outras latitudes do interior argentino, bem como ocorrerá com autores mineiros, paulistas, cariocas, etc, da parte brasileira, os vídeos com o registro das vozes dos próprios escritores não só permitirão que nossa audiência entre em contato com a criação poética nas línguas de origem senão como tomar contato também com 
as gradações e variações linguísticas e de entonação do espanhol argentino e, logo, do português brasileiro. $^{5}$

Ao começar falávamos que ANTEN ]A[ RGENTA é um projeto experimental, e não institucional. Com isso queríamos dizer que lidamos com uma série de problemas técnicos, por exemplo, a qualidade atualmente precária dos canais digitais de realização e gravação das entrevistas. Programas de transmissão em rede geralmente impõem limites temporais ou de recursos para contas gratuitas. Por isso, optamos pelo Jitsi Meet, plataforma que não impõe limites rígidos quanto ao tempo ao uso, bem como permite gravar as entrevistas em seu modo gratuito. Mas a qualidade da gravação (embora hoje os recursos ofertados tenham se tornado mais acessíveis) é ainda sujeita a falhas, a definições de imagem que oscilam e perdem qualidade, entre outros obstáculos que vamos descobrindo nestes tempos em que gradualmente passamos das salas físicas, bem mais propícias à sociabilidade e às dinâmicas insubstituíveis do ensino e aprendizado presencial, às salas digitais que ainda usamos mal. Tais problemas são minimizados (embora não desapareçam) na série “autor@s.leem”. Isso porque os autores gravam seus próprios vídeos caseiros, o que permite uma qualidade levemente superior

\footnotetext{
${ }^{5}$ Ainda que tal questão não tenha norteado nossa atividade, descobri-la, na medida em que fomos selecionando os autores e entrando em contato com os registros linguísticos variados, entendemos que se trata de uma questão propícia a enfrentar algo próximo daquilo que Pier Paolo Pasolini chamou de "genocídio cultural" e "puritanismo industrial" ao eleger o dialeto friuliano (variação linguística do idioma nacional pelo qual optou ao escrever Poemas de Casarsa (1942), seu primeiro livro). "Genocídio cultural” foi o termo que Pasolini cunhou para denunciar os ataques do nacionalismo-fascista de Musolini, ditador para quem o mundo linguístico e rural, a exemplo do contexto friuliano, constituía uma ameaça à unidade linguística, social e ideológica requerida pelo Estado totalitário do período que caracterizou as primeiras produções do poeta e cineasta. E por "puritanismo industrial", entre outras coisas, entende-se os procedimentos de massificação da cultural subalterna italiana e que aparelhava a tentativa de expansão da ideologia totalitária do fascismo na Itália. De modo que optar por escrever em seus primeiros livros (antes de adotar o italiano normativo ao pretender cada vez mais uma "função pública" e uma "poesia civil" no enfrentamento do fascismo italiano) Pasolini reivindicara um plano de intervenções sobre a língua, sobre a literatura, sobre o cinema, tratando com isso de compor seus textos mediante um registro do italiano não-nacional (não fascista, leia-se), pretendendo um resultando poético estratificado, dantesco, heterogêneo e múltiplo. Ainda que no caso de nosso projeto não estejamos lidando com registros deliberadamente dialetais, as variações linguísticas internas ao território e em trânsito, acreditamos, cumpre um papel similar ao oferecer uma espessura heterogênea referente ao espanhol rio-platense e ao português brasileiro - sendo que, em alguns casos específicos, ocorrerá que certos autores pretendidos por nossa seleção terão escrito mediante uma linguagem híbrida entre o espanhol e o português americanos, estes sim pondo em evidência mais sensível a algaravia ignorada pelo projeto do Mercosul (de origem expressamente alfandegária, e não cultural ou linguística, especialmente obstacularizado após os rumos pleiteados pela chamada "Agenda Brasil" e trazida à tona pelo então senador Renan Calheiros durante as reorganizações dos poderes legislativo e o executivo do Brasil durante o processo de substituição parlamentar de Dilma Rousseff por Michel Temer entre 2015 e 2016).
} 
comparada à transmissão por "streaming", conforme acontece nas entrevistas, sujeita a oscilações mais sensíveis na transmissão de dados.

São portanto algumas das estratégias que podemos relatar da tentativa de aquisição de experiência na produção e difusão em redes digitais de conteúdos vinculados às produções crítica, literária e editorial entre os campos argentino e brasileiro. Há obstáculos de ordem técnica, há também as dificuldades pessoais resultantes da rotina de continuidade acerca de um projeto que demanda aplicação de tempo e trabalho não remunerados, competindo assim com outras atividades profissionais de maior importância para nossa sobrevivência financeira e profissional. Seja como for, tem sido uma experiência enriquecedora, por permitir expandir linhas de atuação relacionadas à pesquisa acadêmica, via de regra restringida ao âmbito institucional, e especialmente por permitir (ainda que mínima) linhas de circulação bilaterais entre autores e obras que ainda não circulam entre nós. ${ }^{6}$ Assim seguimos, pensando e debatendo a propósito de linhas de bibliocircularidade que resultaram produtivas em outras épocas, bem com tentando imaginar outras contextualizações diante de uma nova produção de realidade nestes tempos em que o confinamento nos assusta com a determinação solipsista de nossas vidas demandantes de formas de encontro. ANTEN ]A[ RGENTA é uma tentativa nesse caminho de inconstâncias institucionais e editorais no que diz respeito a relações literárias entre Argentina e Brasil.

\section{Referências:}

Endereço da página ANTEN ]A[ RGENTA - https://davisdiniz.wixsite.com/antenargenta

DINIZ, Davidson. "Autores y editores hacia la profesionalización: Monteiro Lobato y la Companhia Nacional | Manuel Gávelz y la Cooperativa Editorial”. In: CROCE, Marcela (dir.). Historia comparada de las literaturas argentina y brasileña. Tomo III. De la crisis bursátil a la caída de los gobiernos populistas (1890-1922). Villa María, Eduvim, 2016, p. 241-264.

\footnotetext{
${ }^{6}$ Como é sabido, a circulação de poesia é ainda mais complicada (dada as restrições mercadológicas) que a narrativa. Um dos motivos pelos quais optamos em divulgar preferencialmente a poesia, gênero mais restrito no que respeita a circulação bilateral.
} 
"Mário de Andrade, Nicolás Olivari y Leopoldo Marechal: mediavalismo y clasicismos en la cuenca Amazonas-Iguazú". In: CROCE, Marcela. Historia comparada de las literaturas argentina y brasileña. Tomo IV. De la vanguardia a la caída de los gobiernos populistas (19221955). Villa María, Eduvim, 2017, p. 119-141.

; RANGEL, Lívia. "Intercambios y traduciones: Benjamín de Garay y Rául Navarro | Newton Freitas y Lídia Besouchet”. In: CROCE, Marcela (dir.). Historia comparada de las literaturas argentina y brasileña. Tomo VI. De la crisis bursátil a la caída de los gobiernos populistas (1822-1955). Villa María: Eduvim, 2016, p. 359-406.

Instinto $(s)$ de transnacionalidade. Ensaio sobre a sociabilidade nos campos literários argentino e brasileiro (1840-1940). (Trabalho de conclusão do período de Bolsa pelo Programa Nacional de Residência em Pesquisa - PNAP-R da Fundação Biblioteca Nacional). Rio de Janeiro: FBN, 2017.

GANDOLFO, Elvio. Ônibus. Literatura argentina. Tradução de Davis [Davidson] Diniz. Rio de Janeiro: Papéis Selvagens, 2019.

MERET, Diego. Na pausa. Literatura argentina. Tradução de Davis [Davidson] Diniz. Rio de Janeiro: Papéis Selvagens, 2021 (prelo).

MICELI, Sergio. Vanguardas em retrocesso: ensaios de história social e intelectual do modernismo latino-americano. São Paulo: Cia das Letras, 2012. 2018 .

Sonhos da periferia. Inteligência argentina e mecenato privado. Todavia: São Paulo,

PIZARNIK, Alejandra. Os trabalhos e as noites. Poesia argentina. Tradução de Davis [Davidson] Diniz. Belo Horizonte: Relicário Edições, 2018.

. Árvore de Diana. Poesia argentina. Tradução de Davis [Davidson] Diniz. Belo Horizonte: Relicário Edições, 2018.

Este é um artigo de acesso aberto distribuído sob os termos da Licença Creative Commons Atribuição Não Comercial-Compartilha Igual (CC BY-NC- 4.0), que permite uso, distribuição e reprodução para fins não comerciais, com a citação dos autores e da fonte original e sob a mesma licença. 